\title{
Clinical neurorestorative progress in stroke
}

This article was published in the following Dove Press journal:

Journal of Neurorestoratology

23 March 2015

Number of times this article has been viewed

\author{
Liyan Qiao',* \\ Jun $\mathrm{Lu}^{2, *}$ \\ Hongyun Huang ${ }^{3-5}$ \\ 'Department of Neurology, \\ Tsinghua University Yuquan \\ Hospital, ${ }^{2}$ Department of Emergency, \\ 2nd Artillery Hospital, ${ }^{3}$ Center \\ of Neurorestoratology, Beijing \\ Rehabilitation Hospital, Capital \\ Medical University, ${ }^{4}$ Beijing Hongtianji \\ Neuroscience Academy, Beijing, \\ ${ }^{5}$ Neuroscience Institute of Taishan \\ Medical University, Shandong, \\ People's Republic of China \\ *These authors are co-first authors
}

Correspondence: Liyan Qiao Department of Neurology, Tsinghua University Yuquan Hospital, No 5 Shijingshan Road, Beijing, People's Republic of China Tel +86 I0 88255293

Email qiaoliyan2000@aliyun.com

Hongyun Huang

Beijing Hongtianji Neuroscience

Academy, Lingxiu Building, No I

Gucheng Street, Beijing, I00 I43,

People's Republic of China

Tel +86 I39 I0I I 6608

Email hongyunh@gmail.com
Abstract: Stroke is the second most common single cause of death worldwide, with over five million deaths per year globally. So far, conventional therapy has failed to restore neurological function poststroke. Neurorestorative strategy has provided therapeutic benefit for the treatment of stroke. This review outlines the clinical advances, in which cell-based neurorestorative strategies offer the broadest range of potential treatments for stroke.

Keywords: stroke, cerebral infarction, treatment, neurorestorative strategy, neurological function recovery, cell therapy

\section{Introduction}

Stroke is identified by the sudden occurrence of a nonconvulsive, focal neurologic deficit. ${ }^{1}$ Among all the neurologic diseases of adult life, stroke ranks first in frequency and impact on disability. Stroke, after ischemic heart disease, is the second commonest single cause of death worldwide, with over five million deaths per year globally. The US Census Bureau has forecasted the distribution of incident stroke cases for the years 2010-2050. Over these 40 years, the number of incident strokes is expected to more than double, with the majority of the increase among the elderly (age $>75$ years) and minority groups (particularly Hispanics). ${ }^{2}$

Cerebral infarction basically comprises two pathophysiologic processes: 1) a loss in the supply of oxygen and glucose secondary to vascular occlusions and 2) an array of changes in cellular metabolism as a consequence of the collapse of energy-producing processes, with damage to cell membranes. Of potential therapeutic importance are the observations that some of the cellular processes leading to neuronal death are not irrevocable and may be reversed by early intervention, either restoration of blood flow or prevention of the influx of calcium into the cell. In the early stage, the most important therapy that can be taken into consideration is thrombolysis with tissue plasminogen activator, which is now a well-established treatment for acute ischemic stroke and is associated with significant improvements in outcomes. ${ }^{3}$ Unfortunately, the time window of 4.5 hours is its limitation. Other therapies for stroke are vascular revascularization and secondary prevention strategies. Vascular revascularization includes carotid endarterectomy and stenting. Secondary prevention strategies are mainly for hypertension, heart disease, atrial fibrillation, diabetes mellitus, cigarette smoking, hyperlipidemia, and antiplatelet, statin, and anticoagulant treatment. Together with the primary prevention concept for stroke, the main purpose of current therapies for stroke patients is to prevent stroke event other than to restore neurological impairment caused by the stroke. 
However, when a stroke event really happens after all the possible treatments mentioned above, what can we do for the brain tissue lesion and how can we restore the functional impairment left by stroke? At first, neuroprotection is the important direction with a purpose to save the dying neuron with no encouraging results. Recently, a trend of switching from neuroprotectant toward neurorestorative approaches has been set on the fact that cerebral plasticity and neurological recovery can be stimulated in the post-acute ischemic brain. Neurorestorative processes include neurogenesis, angiogenesis, and synaptic plasticity, which have been shown to be beneficial for the functional improvement after stroke. In general, neurorestorative therapy includes pharmacological, cell-based, and neuromodulating therapy. ${ }^{4}$ In this review, we outline the clinical neurorestorative strategies with emphasis on cell-based therapy as a promising option for stroke.

\section{Clinical neurorestorative progress Medicines and molecules}

Following cerebral ischemia, a complicated cascade of biochemical events occurs, ultimately leading to the death of neurons. Within this cascade, many molecular targets can be pharmacologically modulated to produce neuroprotection. The potential targets include glutamate release, glutamate receptor activation, excitotoxicity, calcium influx into cells, mitochondrial dysfunction, activation of many intracellular enzymes, free radical production, nitric oxide production, apoptosis, and inflammation.

\section{Radical scavengers}

There is substantial experimental evidence that free radicals are produced in the brain during ischemia, during reperfusion, and during intracranial hemorrhage. Removal of pathologically produced free radicals is therefore a viable approach to neuroprotection. Compounds with free radical-trapping properties (NXY-059) or free radical-scavenging activity (ebselen, edaravone) have been examined in experimental models of stroke and evaluated clinically as neuroprotective agents. The use of NXY-059, a free radical-trapping agent, has been associated with clinical benefits in animal models of stroke. ${ }^{5}$ However, NXY-059 has been shown to be ineffective in acute ischemic stroke patients. ${ }^{6,7}$

As an enzyme mimic for activity of the selenoenzyme GPx, ebselen has been proved to be highly useful in research on mechanisms in redox biology. ${ }^{8}$ It is a multifunctional compound, which catalyzes several essential reactions for the protection of cellular components from oxidative and free radical damage. ${ }^{9}$ It was shown to attenuate oxidative DNA damage and provide protection against neuronal death from stroke in animal models. ${ }^{10}$

Edaravone has been used in acute ischemic stroke in both animal experiments ${ }^{11}$ and clinical settings, and exerts neuroprotective effect on ischemic-injured brains. ${ }^{12}$ Edaravone has been used in patients with acute ischemic stroke in Japan for over 10 years but does not have marketing authorization in Europe or America. ${ }^{13}$ Recombinant tissue plasminogen activator in combination with edaravone improved functional prognosis in stroke patients, which extends its application range for the therapy of stroke. ${ }^{14}$

\section{NMDA antagonists}

Glutamate is the primary excitatory neurotransmitter in the adult brain and a critical transmitter for signaling neurons to degenerate following stroke. The finding led to a number of clinical trials that tested inhibitors of excitotoxicity in stroke patients. Glutamate exerts its function in large by activating the calcium-permeable ionotropic $N$-methyl-d-aspartate (NMDA) receptor. NMDA antagonists, which have been investigated in stroke, include aptiganel hydrochloride, dextrorphan, dextromethorphan, magnesium ion, ifenprodil, and eliprodil, which have been demonstrated to have preclinical neuroprotective efficacy. ${ }^{15,16}$ However, recent findings of a persistent poststroke decline in NMDA receptor density, which plays a pivotal role in plasticity and memory formation, suggest that NMDA receptor stimulation, rather than inhibition, may prove beneficial in the subacute period after stroke. The beneficial role of NMDA receptor stimulation during the recovery period after stroke is most likely due to enhanced neuroplasticity rather than neuroprotection. ${ }^{17}$

\section{Scavenging divalent metal ions}

Zinc is both a direct neurotoxin and a signaling mediator in multiple early and late detrimental processes following ischemia. DP-b99 is a membrane-activated chelator of zinc and calcium ions. ${ }^{18}$ It seemed well tolerated by patients with acute stroke, and a Phase IIb trial reported better outcomes among DP-b99-treated patients than a control group on a secondary outcome measure. ${ }^{19}$ However, in a randomized, double-blind, placebo-controlled, multicenter, parallel-group trial of intravenous (IV) DP-b99 administration in ischemic stroke patients, DP-b99 shows no evidence of efficacy in treating acute human ischemic stroke. ${ }^{18,20}$

\section{Minocycline}

Minocycline is a semisynthetic derivative of the tetracycline group of antibiotics. It has been found to have neuroprotective 
effect in small randomized, controlled human trials, and is a promising neuroprotective agent in acute stroke. However, a large study has not been powered to reliably identify or to exclude a modest, but clinically important, treatment effect of minocycline. ${ }^{21-23}$

\section{Cell therapy}

Stem cells are undifferentiated cells that have the capacity to self-renew and differentiate into a range of tissues. There is substantial evidence showing that the stem cells improve functional recovery and reduce the infarct volume after stroke in the animal models. Clinical trials confirmed the safety and feasibility of some kinds of cell therapy in stroke patients. ${ }^{24}$ Clinical cell-based neurorestorative therapy can be divided into "endogenous" and "exogenous" approaches: the endogenous approach aims to stimulate mobilization of stem/progenitor cells already present within the individual. Granulocyte colony-stimulating factor (G-CSF) is one of the successful examples for endogenous approaches. "Exogenous" approaches mean delivering cells to patients. Cell therapy involves the delivery of cells locally (eg, direct intracerebral [IC] implantation), intrathecally, or systemically (eg, IV or intra-arterial [IA]).

\section{G-CSF}

G-CSF is used to mobilize hematopoietic stem cells into the peripheral blood. However, it has also been shown to have neuroprotective properties beyond simply cell mobilization, and reduces infarct volume in experimental cerebral ischemia. ${ }^{25}$ In the acute phase of cerebral ischemia, the neuroprotective mechanism of G-CSF includes inhibition of glutamate release, reduction of inflammation, antiapoptotic activity, and suppression of edema formation. ${ }^{26}$ G-CSF has been shown to be safe in Phase I clinical trials of human stroke when used within 7 days, ${ }^{27,28}$ or 7-30 days poststroke. ${ }^{29}$ Different doses of G-CSF were safe and well tolerated in acute and subacute ischemic stroke patients. ${ }^{30,31}$ However, although there was a trend for reduced infarct growth, G-CSF treatment failed to show efficacy in functional evaluation in a large Phase II trial in acute ischemic stroke patients. ${ }^{32}$

\section{"Exogenous" cell therapy for stroke}

Grafted cells have been demonstrated to have the ability to survive, differentiate to neurons, and ameliorate functional deficits in the brain of stroke models. Most importantly, grafted cells can migrate toward the lesion with an ischemic stroke following administration. Promising cell source includes embryonic stem cells (ESCs), neural stem/progenitor cells
(NSPCs), immortalized cell lines (NT2 cell line), mesenchymal stromal cells (MSCs), umbilical cord blood cells and related cells, and induced pluripotent stem cells (iPSCs). However, the review only focuses on the cell application in clinical trials.

\section{Bone marrow mononuclear cells (BM-MNCs) and bone} marrow MSCs (BM-MSCs)

BM-MNCs and BM-MSCs in acute/subacute stage of stroke IA autologous BM-MNCs transplantation was performed for acute hemorrhagic ${ }^{33}$ or ischemic stroke. ${ }^{34}$ Patients demonstrated a partial improvement and a slight decrease in the ischemic area by magnetic resonance imaging (MRI) and hypoperfusion by single photon emission computed tomography (SPECT). Some participants showed a good clinical outcome. ${ }^{35} \mathrm{BM}-\mathrm{MNCs}$ and BM-MSCs are also safe, feasible, and effective via an IV route of administration or in patients with subacute ischemic stroke. ${ }^{36,37}$

\section{BM-MNCs and BM-MSCs in chronic stage of stroke}

Autologous BM-MSCs were injected intravenously into 12 patients with stroke. Serial evaluations showed no severe adverse cell-related effects and a trend of functional recovery, ${ }^{38}$ and similar results were reported by IV cell transplantation, ${ }^{39,40}$ and also by IA cell transplantation. ${ }^{41}$ Long-term follow-up is, however, required to provide convincing evidence for their safety. ${ }^{42}$ Additional studies are under way. ${ }^{43}$

\section{Cultured neurons}

The safety and feasibility of intraparenchymal transplantation of neuronal cells derived from human teratocarcinoma were confirmed in patients with basal ganglia stroke and fixed motor deficits. ${ }^{44,45}$ No adverse effects were observed during a 12-month follow-up; ameliorating motor and cognitive impairments, increasing metabolic change as shown by increased fluorodeoxyglucose uptake at the site of implantation. ${ }^{46,47}$ Most importantly, Nelson et $\mathrm{al}^{48}$ reported the first postmortem brain findings of a patient 27 months after transplantation, who died of acute myocardial infarction. Neurofilament immunoreactive neurons were identified in the graft site, and fluorescent in situ hybridization revealed polyploidy in groups of cells at this site, and there was no evidence of a neoplasm after more than 2 years of implantation.

\section{Umbilical cord stromal cells}

Umbilical cord stromal cells have been shown as a feasible and safe approach for the treatment of ischemic stroke patients with potential to improve the neurological function. ${ }^{49,50}$ 


\section{Autologous peripheral blood cells}

After G-CSF mobilization, IC implantation of autologous peripheral blood stromal cells has been shown to be safe, feasible, and effective in stroke patients in a randomized Phase II study. ${ }^{51}$ Wang et al indicated that administration of G-CSF-mobilized autologous CD34-positive cells was safe in patients poststroke. ${ }^{52}$

\section{Other cell type}

Neurotransplantation of fetal porcine cells in patients with basal ganglia infarcts was demonstrated as safe and feasible in a preliminary study. ${ }^{53}$ Two patients showed improvement in speech, language, and/or motor impairments, which persisted at 4 years.

\section{Combination cell therapy}

The possible benefits of transplanting multiple cells were investigated, since substantial evidence indicates the efficacy of independent utility of many kinds of cells, both in animal models and in patients.

Bhasin et $\mathrm{al}^{54}$ recruited 40 chronic stroke patients with treatment with autologous mononuclear and MSCs intravenously. The safety test profile was normal with no mortality or cell-related adverse reactions in patients, and statistically significant improvement found by the assessment of living ability and neurological electrophysiology. A total of ten consecutive stroke patients were treated by combination cell transplantation including olfactory ensheathing cells, neural progenitor cells, umbilical cord mesenchymal cells, and Schwann cells. ${ }^{55}$ After 6 months to 2 years of followup, the patients achieved different degrees of neurological function amelioration including improved speech, muscle strength, muscular tension, balance, pain, and breathing.

We assessed the safety and feasibility of the cotransplantation of neural stem/precursor cells and MSCs in patients with ischemic stroke. ${ }^{56}$ Eight patients were enrolled. All patients had a hemisphere with infarct lesions located on one side of the territories of the cerebral middle or anterior arteries as revealed with cranial MRI. The most common side effect of stem cell transplantation in these cases was low fever that usually lasted 2-4 days after each therapy. One patient exhibited minor dizziness. All side effects appeared within the first 2-24 hours of each cell transplantation and resolved without special treatment. There was no evidence of neurological deterioration or neurological infection. Most importantly, no tumorigenesis was found at a 2-year follow-up. The neurological functions, disability levels, and daily living abilities of the patients in this study were improved. These observations support the use of the combination transplantation of NSPCs and MSCs as a safe and feasible method of improving neurological function.

G-CSF in combination with other cell factors confers greater neuroprotection in ischemic animal models than a solitary treatment. ${ }^{57}$

\section{Neuromodulation}

The effects of repetitive transcranial magnetic stimulation (rTMS) on motor and sensory function recovery in stroke patients have been investigated. For hand motor function recovery after stroke, rTMS of the lesioned or contralesional motor cortex was combined with motor training and showed ambiguous effects; some patients improved, whereas others did not show any rTMS effect. ${ }^{58}$ Central poststroke pain (CPSP) is one of the most refractory chronic pain syndromes. The rTMS of the primary motor cortex has been demonstrated to provide moderate pain relief for CPSP. The mechanism underlying the pain relief is the restoration of abnormal cortical excitability. ${ }^{59}$

Transcranial direct current stimulation (tDCS), a noninvasive neuromodulation technique inducing prolonged brain excitability changes and promoting cerebral plasticity, is a promising option for neurorehabilitation, such as limb function ${ }^{60}$ and aphasia. ${ }^{61}$ The effects of rTMS/tDCS on the functional architecture of the motor system depend upon lesion location, degree of impairment, and number of treatment sessions. Furthermore, analyses of regional brain activity and motor network connectivity allow prediction of the behavioral effects of brain stimulation. ${ }^{62}$

Robotic treatment is effective to reduce motor impairment in chronic stroke patients. ${ }^{63}$ An electromyographydriven hand robot developed for poststroke rehabilitation training showed significant motor, spasticity, and muscle coordination improvements in the hand. ${ }^{64}$ Another Hand Exoskeleton Rehabilitation Robot had benefits in range of motion and grip strength in the hands of poststroke patients. ${ }^{65}$ Robot-aided gait training could provide selective control on one of the essential subtasks of walking. ${ }^{66}$ A prospective, multicenter, parallel-group, randomized trial enrolled patients with motor impairment for more than 6 months and moderate-to-severe arm paresis after a cerebrovascular accident in Switzerland; 38 patients assigned to robotic therapy had greater improvements in motor function in the affected arm over the course of the study. However, the authors pointed out that absolute difference between effects of robotic and conventional therapy was small and of weak significance. ${ }^{67}$ 
A tetraplegia patient with brainstem stroke could perform three-dimensional reaches and grasp movements using a neural interface system-based control of a robotic arm. Although robotic reach and grasp actions were not as fast or accurate as those of an able-bodied person, neural interface system is one of the potential treatments for disability caused by stroke. ${ }^{68}$

\section{Discussion}

Neurorestoratology, a distinct discipline within the neurosciences, has been clearly defined by the International Association of Neurorestoratology as one subdiscipline and one new branch of neuroscience, which studies the therapeutic strategies for neural regeneration, repair, and replacement of damaged components of the nervous system, neuroplasticity, neuroprotection, neuromodulation, angiogenesis, immunomodulation, and their mechanisms to cause improvement. ${ }^{69}$ The core of neurorestoratology is to restore neurological function. The research field of neurorestoratology covers various neurorestorative treatments including factors, medicines, bioengineering, neuromodulation, neuroprotection, and cell therapy. Here we discuss the cell therapy, since we are facing explosive evidence from cell therapy, and cell therapy has been emerged as an optimizing option, especially for the sequela of stroke.

\section{The possible mechanisms of neurorestoration by cell therapy}

For cell therapy, the potential mechanisms of action are incompletely understood. Nevertheless, we have solid evidence from animal models that the possible mechanisms of neurorestoration in stroke are related to cell substitution, secretion of trophic factors, enhanced immunomodulation, angiogenesis, neurogenesis, synaptic connectivity, white matter remodeling, etc. ${ }^{70-72}$ Cell therapies probably act on multiple mechanisms in ischemic stroke, depending upon the timing and mode of administration; however, unlike neuroprotectant drugs, cell therapies have the advantage that they may be able to respond dynamically to an environment that varies both temporally and spatially after ischemia, rather than targeting a single pathway or mechanism of action. ${ }^{25}$

\section{Survival and differentiation of the transplanted cells in stroke lesion}

Following vascular occlusion, a complex chain of events occurs at a molecular level, leading to irreversible tissue injury, including failure of energy synthesis, loss of transmembrane ionic gradients dependent on active transport, cell depolarization, and excitotoxicity due to the excess release of excitatory neurotransmitters. Several events, including edema, deafferentation, and inflammation, occur around the infarct. It is a critical step for the transplanted cells to survive first before they effect. Daadi et $\mathrm{al}^{73}$ transplanted NSPCs derived from ESCs into the poststroke rat brain, and showed that transplanted cells could differentiate into neurons, oligodendrocytes, and astrocytes. Neural progenitor cells derived from murine or monkey ESCs were also reported to survive in stroke lesions of brain, and differentiate into mature neurons. ${ }^{74,75}$ After human neural precursor cells (NPCs) derived from iPSCs were transplanted into the murine brain, they survive as mature neurons ${ }^{76}$ NSPCs could survive and migrate toward the lesion in rats with an ischemic stroke following intracisternal administration. Electron microscopy examination also suggested that the transplanted cells showed signs of neuronal differentiation. ${ }^{77}$ Transplanted MSCs aggressively can migrate toward the damaged central nervous system tissue, promote the recovery of motor function after cerebral infarction, and rescue the host neurons. ${ }^{78,79}$

\section{The efficacy of different administration routes}

The administration route to transfer cells to the lesions caused by stroke includes IA, IV, intracisterna magna, lumbar intrathecal, or IC injection. Administration routes do affect the migration of transplanted stem cells. Zhang et a ${ }^{80}$ tested the efficacy of different administration routes. While IA administration resulted in the highest donor cell number detected within the ischemic brain compared to the other routes, umbilical tissue cell treatments via all routes can provide therapeutic benefit after stroke. IA, IV, and IC seem to bring enhanced benefits due to their ability to increase synaptophysin immunoreactivity and to reduce apoptotic cells. IA and IV are more and more widely accepted due to their convenience. For IA and IV cell transplantation, cell size and velocity of injection are major determinants of the safety. ${ }^{81}$ In acute brain infarction, IA administration showed substantially increased migration and a large number of transplanted human BM-MSCs in the target brain than IV administration. ${ }^{82}$ The effects of transplanted BM-MSCs administered via internal jugular vein injection, carotid artery injection, or intraventricular transplantation for the treatment of cerebral infarction in rats were investigated with increasing trend. ${ }^{83}$ However, for improving functional recovery, reducing lesion size, and increasing vessel density, there were no significant differences between IV and IA groups, although IA led to a greater number of cells in the brain after injection. ${ }^{84}$ 
Recently, a new cell-administering way was observed to gain access to the brain via the nasal cavity and render therapeutic benefits after stroke. ${ }^{85}$

\section{Spatiotemporal dynamics of transplanted cell migration}

An early tissue distribution of BM-MNCs was reported in a chronic stroke patient after an IA delivery. ${ }^{86}$ Part of the cell suspension was radiolabeled with $99 \mathrm{mTc}$ to monitor the fate of transplanted BM-MNCs. Brain SPECT views revealed uptake and retention of the labeled BM-MNCs in the territory of one side of the middle cerebral artery for up to 48 hours. The remaining uptake occurred mainly in the liver and spleen. This distribution is consistent with Correa et al's report. ${ }^{87}$

The fates of human ESC-derived NPCs were investigated for 8 weeks following transplantation into the side contralateral to the infarct region using $7.0 \mathrm{~T}$ animal MRI. MRI analyses indicated that the migrating cells were clearly detectable at the infarct boundary zone by 1 week, and the intensity of the MRI signals robustly increased within 4 weeks after transplantation. Afterward, the signals were slightly increased or unchanged. ${ }^{88}$ Also, neural stem cells have the ability to migrate to the frontal and parietal lobes, caudate, and putamen. ${ }^{89}$ One of the ways of aggressive migration toward the lesion is through the corpus callosum..$^{90}$

\section{Preconditioning strategy in cell transplantation therapy}

Massive grafted cell death and low survival rate in cell therapy are the limitations of cell therapy. The approach of preconditioning stem cells became an attractive option due to its high cell viability after transplantation. Preconditioning stem cells via cytokines, chemical drugs, and hypoxia has been demonstrated to increase grafted stem cell survival, proliferation, migration to ischemic perifocal area, and ultimately improve neurobehavioral outcomes. ${ }^{91}$ Ischemic/hypoxic preconditioning activates endogenous defense mechanisms that show marked protective effects against multiple insults found in ischemic stroke and other acute attacks. A sublethal hypoxic exposure significantly increases the tolerance and regenerative properties of cells. So far, a variety of preconditioning triggers have been tested on different cells. Preconditioned cells generally show much better cell survival, increased neuronal differentiation, enhanced paracrine effects leading to increased trophic support, and improved homing to the lesion site. ${ }^{92}$

\section{Conclusion}

Although there are major advances in understanding the pathophysiology of cerebral ischemia, therapeutic options for acute ischemic stroke remain very limited. For the sequelae of chronic stage of stroke, few of the treatment options have proven efficacious in clinical studies despite tremendous progress in preclinical studies. Cell-based neurorestorative strategies for stroke may have efficacy in the improvement of neurological outcome and quality of life of patients in the acute or chronic stage of stroke. Further investment in cellbased therapy for the neurorestorative treatment of stroke is therefore warranted.

\section{Acknowledgment}

The authors are very appreciative for the modification by Professor Michael Chopp from the Department of Neurology at the Henry Ford Hospital, Detroit, MI, USA.

\section{Disclosure}

The authors report no conflicts of interest in this work.

\section{References}

1. Victor M, Ropper AH. Adams and Victor's Principle of Neurology. 7th ed. New York: McGraw-Hill; 2001.

2. Howard G, Goff DC. Population shifts and the future of stroke: forecasts of the future burden of stroke. Ann NY Acad Sci. 2012;1268:14-20.

3. Kirkman MA, Citerio G, Smith M. The intensive care management of acute ischemic stroke: an overview. Intensive Care Med. 2014;40(5):640-653.

4. Gopurappilly R, Pal R, Mamidi MK, Dey S, Bhonde R, Das AK. Stem cells in stroke repair: current success and future prospects. CNS Neurol Disord Drug Targets. 2011;10(6):741-756.

5. Green AR, Ashwood T. Free radical trapping as a therapeutic approach to neuroprotection in stroke: experimental and clinical studies with NXY-059 and free radical scavengers. Curr Drug Targets CNS Neurol Disord. 2005;4(2):109-118.

6. Diener HC, Lees KR, Lyden P, et al; SAINT I and II Investigators. NXY-059 for the treatment of acute stroke: pooled analysis of the SAINT I and II trials. Stroke. 2008;39(6):1751-1758.

7. Shuaib A, Lees KR, Lyden P, et al; SAINT II Trial Investigators. NXY-059 for the treatment of acute ischemic stroke. $N$ Engl J Med. 2007;357(6):562-571.

8. Parnham MJ, Sies H. The early research and development of ebselen. Biochem Pharmacol. 2013;86(9):1248-1253.

9. Azad GK, Tomar RS. Ebselen, a promising antioxidant drug: mechanisms of action and targets of biological pathways. Mol Biol Rep. 2014;41(8):4865-4879.

10. He M, Xing S, Yang B, et al. Ebselen attenuates oxidative DNA damage and enhances its repair activity in the thalamus after focal cortical infarction in hypertensive rats. Brain Res. 2007;1181:83-92.

11. Wu HY, Tang Y, Gao LY, et al. The synergetic effect of edaravone and borneol in the rat model of ischemic stroke. Eur J Pharmacol. 2014; 740:522-531.

12. Ishibashi A, Yoshitake $Y$, Adachi H. Investigation of effect of edaravone on ischemic stroke. Kurume Med J. 2013;60(2):53-57.

13. Wu S, Sena E, Egan K, Macleod M, Mead G. Edaravone improves functional and structural outcomes in animal models of focal cerebral ischemia: a systematic review. Int J Stroke. 2014;9(1):101-106. 
14. Takenaka K, Kato M, Yamauti K, Hayashi K. Simultaneous administration of recombinant tissue plasminogen activator and edaravone in acute cerebral ischemic stroke patients. J Stroke Cerebrovasc Dis. 2014;23(10):2748-2752.

15. Ogden KK, Traynelis SF. New advances in NMDA receptor pharmacology. Trends Pharmacol Sci. 2011;32(12):726-733.

16. Kalia LV, Kalia SK, Salter MW. NMDA receptors in clinical neurology: excitatory times ahead. Lancet Neurol. 2008;7(8):742-755.

17. Dhawan J, Benveniste H, Luo Z, Nawrocky M, Smith SD, Biegon A. A new look at glutamate and ischemia: NMDA agonist improves long-term functional outcome in a rat model of stroke. Future Neurol. 2011;6(6):823-834.

18. Diener HC, Schneider D, LamplY, Bornstein NM, KozakA, Rosenberg G. DP-b99, a membrane-activated metal ion chelator, as neuroprotective therapy in ischemic stroke. Stroke. 2008;39(6):1774-1778.

19. Rosenberg G, Bornstein N, Diener HC, Gorelick PB, Shuaib A, Lees K; MACSI investigators. The membrane-activated chelator stroke intervention (MACSI) trial of DP-b99 in acute ischemic stroke: a randomized, double-blind, placebo-controlled, multinational pivotal phase III study. Int J Stroke. 2011;6(4):362-367.

20. Lees KR, Bornstein N, Diener HC, Gorelick PB, Rosenberg G, Shuaib A; MACSI Investigators. Results of membrane-activated chelator stroke intervention randomized trial of DP-b99 in acute ischemic stroke. Stroke. 2013;44(3):580-584.

21. Kohler E, Prentice DA, Bates TR, et al. Intravenous minocycline in acute stroke: a randomized, controlled pilot study and meta-analysis. Stroke. 2013;44(9):2493-2499.

22. Lampl Y, Boaz M, Gilad R, et al. Minocycline treatment in acute stroke: an open-label, evaluator-blinded study. Neurology. 2007;69(14): 1404-1410.

23. Padma Srivastava MV, Bhasin A, Bhatia R, et al. Efficacy of minocycline in acute ischemic stroke: a single-blinded, placebo-controlled trial. Neurol India. 2012;60(1):23-28.

24. Kalladka D, Muir KW. Brain repair: cell therapy in stroke. Stem Cells Cloning. 2014;7:31-44.

25. England TJ, Gibson CL, Bath PM. Granulocyte-colony stimulating factor in experimental stroke and its effects on infarct size and functional outcome: a systematic review. Brain Res Rev. 2009;62(1):71-82.

26. Abe K, Yamashita T, Takizawa S, Kuroda S, Kinouchi H, Kawahara N. Stem cell therapy for cerebral ischemia: from basic science to clinical applications. J Cereb Blood Flow Metab. 2012;32(7):1317-1331.

27. Shyu WC, Lin SZ, Lee CC, Liu DD, Li H. Granulocyte colony-stimulating factor for acute ischaemic stroke: a randomized controlled trial. CMAJ. 2006;174:927-933.

28. Zhang JJ, Deng M, Zhang Y, et al. A short-term assessment of recombinant granulocyte-stimulating factor (RHG-CSF) in treatment of acute cerebral infarction. Cerebrovasc Dis. 2006;22:323.

29. Sprigg N, Bath PM, Zhao L, et al. Granulocyte-colony stimulating factor mobilises bone marrow stem cells in patients with subacute ischemic stroke: the STEMS pilot randomised controlled trial. Stroke. 2006;37:2979-2983.

30. Moriya Y, Mizuma A, Uesugi T, et al. Phase I study of intravenous low-dose granulocyte colony-stimulating factor in acute and subacute ischemic stroke. J Stroke Cerebrovasc Dis. 2013;22(7):1088-1097.

31. England TJ, Abaei M, Auer DP, et al. Granulocyte-colony stimulating factor for mobilizing bone marrow stem cells in subacute stroke: the stem cell trial of recovery enhancement after stroke 2 randomized controlled trial. Stroke. 2012;43(2):405-411.

32. Ringelstein EB, Thijs V, Norrving B, et al; AXIS 2 Investigators. Granulocyte colony-stimulating factor in patients with acute ischemic stroke: results of the AX200 for ischemic stroke trial. Stroke. 2013;44(10):2681-2687.

33. Mendonça ML, Freitas GR, Silva SA, et al. Safety of intra-arterial autologous bone marrow mononuclear cell transplantation for acute ischemic stroke. Arq Bras Cardiol. 2006;86(1):52-55.

34. Moniche F, Gonzalez A, Gonzalez-Marcos JR, et al. Intra-arterial bone marrow mononuclear cells in ischemic stroke: a pilot clinical trial. Stroke. 2012;43(8):2242-2244.
35. Friedrich MA, Martins MP, Araújo MD, et al. Intra-arterial infusion of autologous bone marrow mononuclear cells in patients with moderate to severe middle cerebral artery acute ischemic stroke. Cell Transplant. 2012;21(Supp1 1):S13-S21.

36. Savitz SI, Misra V, Kasam M, et al. Intravenous autologous bone marrow mononuclear cells for ischemic stroke. Ann Neurol. 2011;70(1):59-69.

37. Honmou O, Houkin K, Matsunaga T, et al. Intravenous administration of auto serum-expanded autologous mesenchymal stem cells in stroke. Brain. 2011;134(Pt 6):1790-1807.

38. Honmou O. Cell therapy for stroke. Rinsho Shinkeigaku. 2013;53(11): 1175-1176.

39. Bringas ML, Suarez C, Sanchez C, et al. Cognitive changes after stem cell transplantation in a patient with subcortical stroke. BMJ Case Rep. 2011: doi 10.1136/bcr.03.2011.3944.

40. Suárez-Monteagudo C, Hernández-Ramírez P, Alvarez-González L, et al. Autologous bone marrow stem cell neurotransplantation in stroke patients. An open study. Restor Neurol Neurosci. 2009;27(3): 151-161.

41. Battistella V, de Freitas GR, da Fonseca LM, et al. Safety of autologous bone marrow mononuclear cell transplantation in patients with nonacute ischemic stroke. Regen Med. 2011;6(1):45-52.

42. Lee JS, Hong JM, Moon GJ, Lee PH, Ahn YH, Bang OY; STARTING collaborators. A long-term follow-up study of intravenous autologous mesenchymal stem cell transplantation in patients with ischemic stroke. Stem Cells. 2010;28(6):1099-1106.

43. Kim SJ, Moon GJ, Chang WH, Kim YH, Bang OY. STARTING-2 (stem cell application researches and trials in neurology-2) collaborators. Intravenous transplantation of mesenchymal stem cells preconditioned with early phase stroke serum: current evidence and study protocol for a randomized trial. Trials. 2013;14(1):317-328.

44. Kondziolka D, Wechsler L, Goldstein S, et al. Transplantation of cultured human neuronal cells for patients with stroke. Neurology. 2000;55:565-569.

45. Kondziolka D, Steinberg GK, Wechsler L, et al. Neurotransplantation for patients with subcortical motor stroke: a phase 2 randomized trial. J Neurosurg. 2005;103(1):38-45.

46. Meltzer CC, Kondziolka D, Villemagne VL, et al. Serial [18F] fluorodeoxyglucose positron emission tomography after human neuronal implantation for stroke. Neurosurgery. 2001;49(3):586-591.

47. Stilley CS, Ryan CM, Kondziolka D, Bender A, DeCesare S, Wechsler L. Changes in cognitive function after neuronal cell transplantation for basal ganglia stroke. Neurology. 2004;63(7):1320-1322.

48. Nelson PT, Kondziolka D, Wechsler L, et al. Clonal human (hNT) neuron grafts for stroke therapy: neuropathology in a patient 27 months after implantation. Am J Pathol. 2002;160(4):1201-1206.

49. Jiang Y, Zhu W, Zhu J, Wu L, Xu G, Liu X. Feasibility of delivering mesenchymal stem cells via catheter to the proximal end of the lesion artery in patients with stroke in the territory of the middle cerebral artery. Cell Transplant. 2013;22(12):2291-2298.

50. Liu X, Ye R, Yan T, et al. Cell based therapies for ischemic stroke: from basic science to bedside. Prog Neurobiol. 2014;115:92-115.

51. Chen DC, Lin SZ, Fan JR, et al. Intracerebral implantation of autologous peripheral blood stem cells in stroke patients: a randomized phase II study. Cell Transplant. 2014; 23(12): 1599-1612.

52. Wang L, Ji H, Li M, et al. Intrathecal administration of autologous CD34 positive cells in patients with past cerebral infarction: a safety study. ISRN Neurol. 2013;2013:128591.

53. Savitz SI, Dinsmore J, Wu J, Henderson GV, Stieg P, Caplan LR. Neurotransplantation of fetal porcine cells in patients with basal ganglia infarcts: a preliminary safety and feasibility study. Cerebrovasc Dis. 2005;20(2):101-107.

54. Bhasin A, Srivastava MV, Mohanty S, Bhatia R, Kumaran SS, Bose S. Stem cell therapy: a clinical trial of stroke. Clin Neurol Neurosurg. 2013;115(7):1003-1108.

55. Chen L, Xi H, Huang H, et al. Multiple cell transplantation based on an intraparenchymal approach for patients with chronic phase stroke. Cell Transplant. 2013;22(Supp1 1):S83-S91. 
56. Qiao LY, Huang FJ, Zhao M, et al. A two-year follow-up study of co-transplantation with neural stem/precursor cells and mesenchymal stromal cells in ischemic stroke patients. Cell Transplant. 2014; 23(Suppl 1):S65-S72.

57. Doycheva D, Shih G, Chen H, Applegate R, Zhang JH, Tang J. Granulocyte-colony stimulating factor in combination with stem cell factor confers greater neuroprotection after hypoxic-ischemic brain damage in the neonatal rats than a solitary treatment. Transl Stroke Res. 2013;4(2):171-178.

58. Le Q, Qu Y, Tao Y, Zhu S. Effects of repetitive transcranial magnetic stimulation on hand function recovery and excitability of the motor cortex after stroke: a meta-analysis. Am J Phys Med Rehabil. 2014;93(5): $422-430$.

59. Hosomi K, Kishima H, Oshino S, et al. Cortical excitability changes after high-frequency repetitive transcranial magnetic stimulation for central poststroke pain. Pain. 2013;154(8):1352-1357.

60. Meinzer M, Lindenberg R, Sieg MM, Nachtigall L, Ulm L, Flöel A. Transcranial direct current stimulation of the primary motor cortex improves word-retrieval in older adults. Front Aging Neurosci. 2014;6:253.

61. Monti A, Ferrucci R, Fumagalli M, et al. Transcranial direct current stimulation (tDCS) and language. J Neurol Neurosurg Psychiatry. 2013;84(8):832-842.

62. Grefkes C, Fink GR. Disruption of motor network connectivity post-stroke and its noninvasive neuromodulation. Curr Opin Neurol. 2012;25(6):670-675.

63. Mazzoleni S, Sale P, Franceschini M, et al. Effects of proximal and distal robot-assisted upper limb rehabilitation on chronic stroke recovery. NeuroRehabilitation. 2013;33(1):33-39.

64. Hu XL, Tong KY, Wei XJ, Rong W, Susanto EA, Ho SK. The effects of post-stroke upper-limb training with an electromyography (EMG)driven hand robot. J Electromyogr Kinesiol. 2013;23(5):1065-1074.

65. Godfrey SB, Holley RJ, Lum PS. Clinical effects of using HEXORR (hand exoskeleton rehabilitation robot) for movement therapy in stroke rehabilitation. Am J Phys Med Rehabil. 2013;92(11):947-958.

66. Koopman B, van Asseldonk EH, van der Kooij H. Selective control of gait subtasks in robotic gait training: foot clearance support in stroke survivors with a powered exoskeleton. J Neuroeng Rehabil. 2013;10:3.

67. Klamroth-Marganska V, Blanco J, Campen K, et al. Three-dimensional, task-specific robot therapy of the arm after stroke: a multicentre, parallel-group randomised trial. Lancet Neurol. 2014;13(2):159-166.

68. Hochberg LR, Bacher D, Jarosiewicz B, et al. Reach and grasp by people with tetraplegia using a neurally controlled robotic arm. Nature. 2012;485(7398):372-375.

69. Huang H, Chen L, Sanberg P. Cell therapy from bench to bedside translation in CNS neurorestoratology era. Cell Med. 2010;1(1):15-46.

70. Shehadah A, Chen J, Pal A, et al. Human placenta-derived adherent cell treatment of experimental stroke promotes functional recovery after stroke in young adult and older rats. PLoS One. 2014;9(1):e86621.

71. Sun C, Sun H, Wu S, et al. Conditional ablation of neuroprogenitor cells in adult mice impedes recovery of poststroke cognitive function and reduces synaptic connectivity in the perforant pathway. J Neurosci. 2013;33(44):17314-17325.

72. Hermann DM, Chopp M. Promoting brain remodelling and plasticity for stroke recovery: therapeutic promise and potential pitfalls of clinical translation. Lancet Neurol. 2012;11(4):369-380.

73. Daadi MM, Li Z, Arac A, et al. Molecular and magnetic resonance imaging of human embryonic stem cell-derived neural stem cell grafts in ischemic rat brain. Mol Ther. 2009;17:1282-1291.

74. Bühnemann C, Scholz A, Bernreuther C, et al. Neuronal differentiation of transplanted embryonic stem cell-derived precursors in stroke lesions of adult rats. Brain. 2006;129:3238-3248.
75. Hayashi J, Takagi Y, Fukuda H, et al. Primate embryonic stem cellderived neuronal progenitors transplanted into ischemic brain. J Cereb Blood Flow Metab. 2006;26:906-914.

76. Chen SJ, Chang CM, Tsai SK, et al. Functional improvement of focal cerebral ischemia injury by subdural transplantation of induced pluripotent stem cells with fibrin glue. Stem Cells Dev. 2010;19:1757-1767.

77. Zhang ZG, Jiang Q, Zhang R, et al. Magnetic resonance imaging and neurosphere therapy of stroke in rat. Ann Neurol. 2003;53:259-263.

78. Kuroda S, Shichinohe H, Houkin K, Iwasaki Y. Autologous bone marrow stromal cell transplantation for central nervous system disorders - recent progress and perspective for clinical application. J Stem Cell Regen Med. 2011;7:1-12.

79. Uccelli A, Moretta L, Pistoia V. Mesenchymal stem cells in health and disease. Nat Rev Immunol. 2008;8:726-736.

80. Zhang L, Li Y, Romanko M, et al. Different routes of administration of human umbilical tissue-derived cells improve functional recovery in the rat after focal cerebral ischemia. Brain Res. 2012;1489:104-112.

81. Janowski M, Lyczek A, Engels C, et al. Cell size and velocity of injection are major determinants of the safety of intracarotid stem cell transplantation. J Cereb Blood Flow Metab. 2013;33(6):921-927.

82. Byun JS, Kwak BK, Kim JK, Jung J, Ha BC, Park S. Engraftment of human mesenchymal stem cells in a rat photothrombotic cerebral infarction model: comparison of intra-arterial and intravenous infusion using MRI and histological analysis. J Korean Neurosurg Soc. 2013;54(6):467-476.

83. Ruan GP, Han YB, Wang TH, et al. Comparative study among three different methods of bone marrow mesenchymal stem cell transplantation following cerebral infarction in rats. Neurol Res. 2013;35(2):212-220.

84. Yang B, Migliati E, Parsha K, et al. Intra-arterial delivery is not superior to intravenous delivery of autologous bone marrow mononuclear cells in acute ischemic stroke. Stroke. 2013;44(12):3463-3472.

85. Wei N, Yu SP, Gu X, et al. Delayed intranasal delivery of hypoxicpreconditioned bone marrow mesenchymal stem cells enhanced cell homing and therapeutic benefits after ischemic stroke in mice. Cell Transplant. 2013;22:977-991.

86. Barbosa da Fonseca LM, Battistella V, de Freitas GR, et al. Early tissue distribution of bone marrow mononuclear cells after intra-arterial delivery in a patient with chronic stroke. Circulation. 2009;120(6): 539-541.

87. Correa PL, Mesquita CT, Felix RM, et al. Assessment of intra-arterial injected autologous bone marrow mononuclear cell distribution by radioactive labeling in acute ischemic stroke. Clin Nucl Med. 2007; 32(11):839-841.

88. Chang DJ, Oh SH, Lee N, et al. Contralaterally transplanted human embryonic stem cell-derived neural precursor cells (ENStem-A) migrate and improve brain functions in stroke-damaged rats. Exp Mol Med. 2013;15(45):e53.

89. Dai J, Li SQ, Qiu YM, et al. Migration of neural stem cells to ischemic brain regions in ischemic stroke in rats. Neurosci Lett. 2013;552: 124-128.

90. Shichinohe H, Yamauchi T, Saito H, Houkin K, Kuroda S. Bone marrow stromal cell transplantation enhances recovery of motor function after lacunar stroke in rats. Acta Neurobiol Exp (Wars). 2013;73(3):354-363.

91. Cai H, Zhang Z, Yang GY. Preconditioned stem cells: a promising strategy for cell-based ischemic stroke therapy. Curr Drug Targets. 2014;15(8):771-779.

92. Yu SP, Wei Z, Wei L. Preconditioning strategy in stem cell transplantation therapy. Transl Stroke Res. 2013;4(1):76-88. 
Journal of Neurorestoratology

\section{Publish your work in this journal}

The Journal of Neurorestoratology is an international, peer-reviewed, open access online journal publishing original research and review articles on the subject of Neurorestoratology. To provide complete coverage of this revolutionary field the Journal of Neurorestoratology wil report on relevant experimental research, technological advances, and
Dovepress

clinical achievements. The manuscript management system is completely online and includes a very quick and fair peer-review system, which is all easy to use. Visit http://www.dovepress.com/testimonials.php to read real quotes from published authors.

Submit your manuscript here: http://www.dovepress.com/journal-of-neurorestoratology-journal 